\title{
Células Troncales Derivadas del Tejido Adiposo
}

\author{
Adipose Tissue Derived Stem Cells
}

*Manuel Meruane \& ${ }^{* * *}$ Mariana Rojas

\begin{abstract}
MERUANE, M. \& ROJAS, M. Células troncales derivadas del tejido adiposo. Int. J. Morphol., 28(3):879-889, 2010.
RESUMEN: Con el objeto de regenerar órganos y funciones se han estudiado las células troncales. Las células troncales adultas poseen la ventaja que pueden ser obtenidas de individuos adultos sin los problemas éticos que trae el uso de células embriónicas. La obtención de células troncales desde el tejido adiposo (ASCs) ha sido una revolución el tema ya que estas células pueden ser obtenidas en grandes cantidades, con mínimo disconfort y hasta con anestesia local. Si comparamos las ASCs versus las células troncales derivadas de la médula ósea (BM-MSCs) sus características fenotípicas y el potencial de diferenciación son muy similares. En esta revisión veremos la técnica de obtención de ACSs, sus características moleculares, su capacidad de diferenciación en los linajes mesodérmicos y no mesodérmicos, los estudios preclínicos y clínicos más importantes realizados, así como las perspectivas en el uso a futuro.
\end{abstract}

PALABRAS CLAVE: Células troncales; Tejido adiposo.

\section{INTRODUCCIÓN}

Uno de los objetivos de la medicina ha sido reestablecer la anatomía y función normal de órganos luego de algún tipo de lesión, de acuerdo a esto se ha trabajado en profundizar los conocimientos sobre regeneración tisular y se ha observado que algunos organismos como la planaria pueden regenerar sus órganos como un proceso habitual (Nogi \& Levin, 2005). Otros anfibios como la salamandra pueden regenerar miembros a través de un proceso de desdiferenciación (Davenport, 2005). En la especie humana sólo el hígado puede regenerarse recuperando su tamaño y función inicial luego de una resección (Elwood \& Pomposelli, 2006), el resto de los órganos incluyendo la piel (Singer \& Clark, 1999) no pueden regenerarse por completo.

La medicina regenerativa y la ingeniería tisular tienen como objetivo perfeccionar la reparación tisular y llegar a regenerar tejidos combinando el estudio de factores de crecimiento, biomateriales y células troncales (Butler \& Gloldstein, 2000).

Por definición una célula troncal se caracteriza por su habilidad de autorenovarse y diferenciarse en múltiple líneas celulares. Las alternativas de células troncales disponibles son: células troncales embriónicas (Embryonic Stem
Cells, ESCs) y células troncales adultas. Aunque el potencial terapéutico de las ESCs parece enorme debido a su gran capacidad de renovación y pluripotencialidad, hay limitaciones prácticas y éticas en su utilización. A diferencia del tipo adulto que es posible de obtener de varios tejidos ya desarrollados no posee tales limitaciones, a este tipo se les denomina células troncales mesenquimales (Mesenchymal Stem Cells, MSCs).

Las MSCs corresponden células de origen mesodérmico, se las considera multipotenciales con autorrenovación limitada y con capacidad de dar origen a tejidos de la misma capa embrionaria, aunque debido a las publicaciones actuales que muestran diferenciación a tejidos de otro origen embrionario podrían pasar a la categoría de pluripotenciales (Fig. 1).

Las primeras MSC estudiadas han sido las obtenidas desde la médula ósea, la evidencia que muestra la existencia de estas células no-hematopoyéticas que podían diferenciarse en otras células mesenquimáticas fue publicado por Friedentein et al. (1974). Posteriormente su estudio ha demostrado la potencialidad para diferenciarse en líneas celulares adipogénicas, osteogénicas, condrogénicas,

\footnotetext{
* Programa Magister en Cs. Biomédicas, Mención Morfología, Facultad de Medicina, Universidad de Chile.

** Laboratorio de Embriología Comparada. Programa de Anatomía y Biología del Desarrollo, Fac. de Medicina, Universidad de Chile.
} 


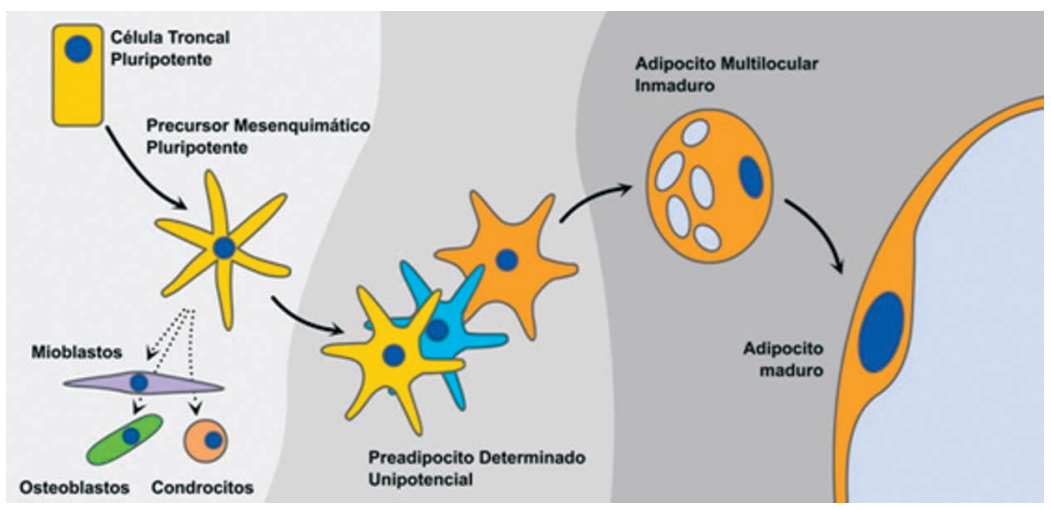

Fig. 1. Secuencia de diferenciación del adipocito. El precursor mesenquimático es pluripotente, se encuentra en el tejido adiposo adulto y puede diferenciarse en otro linaje mesodérmico.

miogénicas y neurogénicas in vitro (Pittenger et al., 1999), así como su potencialidad para ser utilizadas clínicamente con éxito para el tratamiento de enfermedadedes como la coronaria aguda, esclerosis lateral amiotrófica, enfermedad injerto v/s huesped en transplantes y osteogénesis imperfecta (Giordano et al., 2007; Chamberlain et al., 2007). El problema que reviste la obtención desde la médula ósea es que es doloroso, requiere con frecuencia anestesia espinal y la concentración de MSCs obtenidas luego del proceso es baja, lo que necesita varios cultivos in Vitro para obtener un número útil, con el riesgo de contaminación y pérdida (Pittenger et al.; Giordano et al.; Chamberlain et al.; Bruder et al., 1997).

Actualmente se conoce la presencia de células troncales en varios otros tejidos, presentes ahí con el fin de mantener y reparar (Young et al., 2002), se ubican en el tejido conectivo principalmente de órganos de origen mesodérmico. Por este hecho se ha identificado el tejido adiposo como fuente ideal, ya que permite obtener de forma fácil, con mínimo disconfort para el paciente un gran número de células que pueden proliferar en cultivo (Zuk et al., 2001). A las células troncales obtenidas del tejido adiposo las denominaremos ASCs (Adipose-derived Stem Cells).

El tejido adiposo posee la habilidad de cambiar de volumen durante la vida de un individuo, los cambios menores son por hipertrofia celular, pero los cambios mayores son mediados por hiperplasia y aumento de la vascularización. Estos cambios están mediados por una población de células troncales multipotentes con propiedades similares a las obtenidas desde la médula ósea (Fraser et al., 2006).

Según Gimble et al. (2007) para que las células troncales puedan ser utilizadas con fines médicos deben cumplir con los siguientes criterios:

1. Presencia en cantidades muy abundantes (millones a billones de células)
2. Aislables con procedimientos mínimamente invasivos.

3. Diferenciables en múltiples linajes célulares de manera regulable y reproducible.

4. Transplantables en forma autóloga o alogénica.

5. Manipulables de acuerdo a las actuales Guías de Buena Práctica.

¿Por qué Preferir las ASCs? Claramente las ASCs cumplen los criterios de Glimble et al. Considerando la incidencia de obesidad en la población actual, esta es una fuente realmente abundante y accesible. El tejido adiposo puede ser obtenido mediante lipoaspiración en grandes cantidades y con riesgo mínimo. La lipoaspiración es el $3^{\circ}$ procedimiento que con mayor frecuencia realizan los cirujanos plásticos en Norteamérica (ASPS 2007). Según datos desde 1994 al año 2000 se han reportado 0 muertes en 66570 procedimientos y complicaciones serias en 0.68 por 1000 casos (Housman et al., 2002). Con anestesia local se pueden obtener hasta $200 \mathrm{~g}$ de tejido. $1 \mathrm{~g}$ de tejido adiposo contiene $5 \mathrm{x}$ $10^{3}$ ASCs, aproximadamente 500 veces más que $1 \mathrm{~g}$ médula ósea (Fraser et al.).

Consideraciones del tejido adiposo. El tejido adiposo deriva de la capa mesodérmica del embrión y tiene desarrollo pre y post natal. La formación de células adiposas en la especie humana tiene lugar durante el segundo trimestre de gestación (Ailhaud \& Grimaldi, 1992). Se caracterizan por su aspecto fibroblástico que contiene abundante retículo endoplasmático, un alto índice núcleo/citoplasma, localización perinuclear de la mitocondria y la presencia de vacuolas lipídicas (Gimble et al.). Su diferenciación celular procede de la secuencia adipoblasto-Preadipocito-Adipocito inmaduro-adipocito maduro (Fig.1). En el tejido adiposo los precursores coexisten en conjunto con células adiposas maduras, fibroblastos, células sanguíneas, células endoteliales, pericitos y células mesenquimales indifenciadas y pobremente diferenciadas, que hoy llamamos MSCs (Ailhaud \& Grimaldi). Probablemente el progenitor de los adipocitos ha venido desde la médula ósea a través de la circulación (Hausman \& Hausman, 2006). 
Recolección en frasco

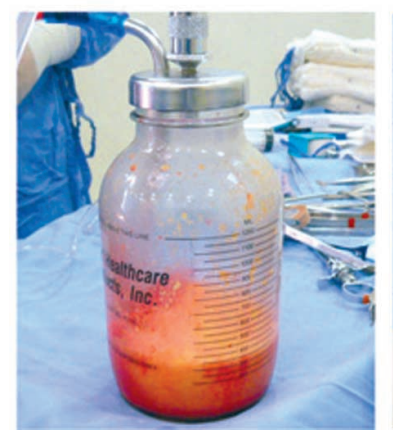

Recolección con jeringa

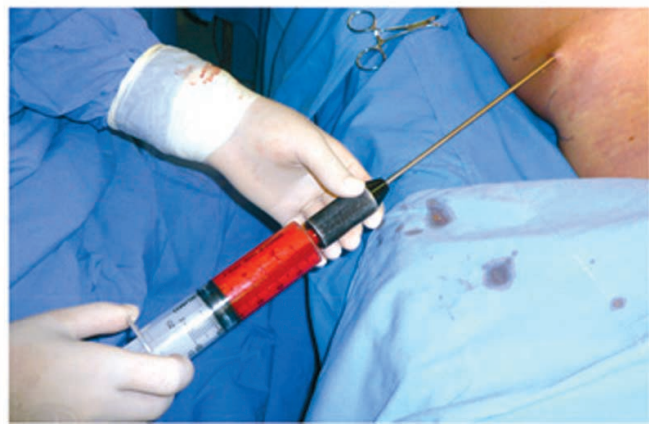

Fig. 2. Proceso de lipoaspiración. A la izquierda se observa la recolección del tejido adiposo lipoaspirado en frasco, a la derecha en jeringa conectada directamente la cánula.

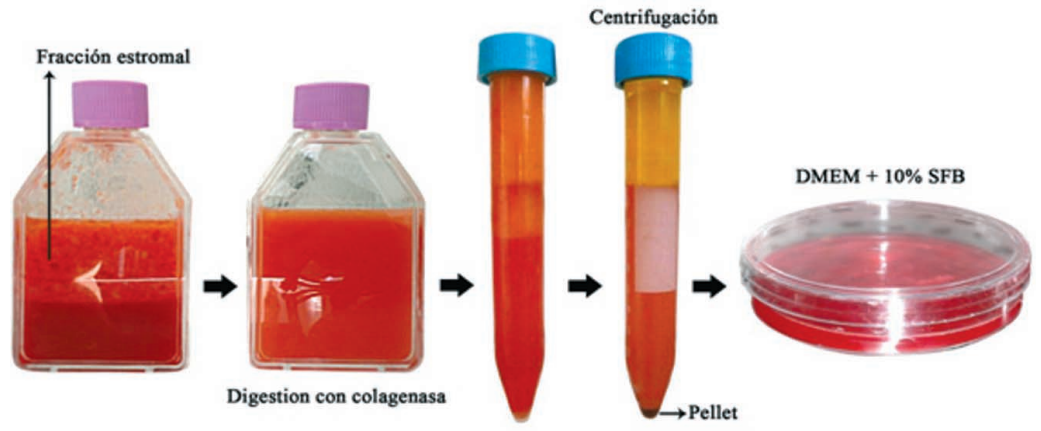

Fig. 3. Técnica de obtención de las células troncales. El tejido adiposo aspirado se compone de una fracción estromal que es digerida con colagenasa para luego ser centrifugada obteniendo un pellet alto en ASCs que es cultivado.

Macroscópicamente se distinguen 5 tipos de tejido adiposo: de la médula ósea, de la grasa parda, de la grasa blanca, el mamario y el de soporte mecánico.

El de la médula ósea ocupa el espacio no necesario para la hematopoyesis. El tejido pardo es muy termogénico, rodea órganos mayores durante en el recién nacido para luego desaparecer en el adulto. El tejido graso mamario provee nutrientes y energía durante la lactancia y es regulado por hormonas del embarazo. El tejido adiposo de soporte mecánico se encuentra en la grasa orbitaria y en palma de mano, planta de pies, no presenta mayores cambios ante la influencia o hormonal. Por último el tejido adiposo blanco provee energía y aislamiento, es reconocido actualmente como un órgano endocrino que secreta adiponectina, leptina y otras adipokinas con efectos fisiológicos y es el que presenta mayores cambios en volumen a lo lago de la vida (Gimble et al.).

El procedimiento de lipoaspiración se realiza a nivel del tejido blanco del tronco y extremidades, la abundancia celular así como su capacidad proliferativa presenta datos contradictorios. Según Almeida et al. (2008). las áreas del tronco presentan un 22\% más de ASCs que las extremidades. Shipper et al. (2008), que evalúan la capacidad proliferativa celular, encuentran que ésta es igualmente alta en todos los depósitos grasos de pacientes jóvenes a diferencia de pacientes de edad avanzada donde es mayor en extremidades.
Técnica de Obtención y Cultivo. El paciente puede ser anestesiado con anestesia general, regional o local. El tejido adiposo puede ser obtenido por resección quirúrgica, por lipoaspiración tumescente o lipoaspiración ultrasónica. En el caso de la técnica tumescente la infiltración del tejido adiposo se realiza con solución fisiológica más epinefrina en concentración de $1 \mathrm{mg} / 1000 \mathrm{ml}$ y si se requiere además anestesia local la concentración de lidocaína a utilizar es de 400mg/1000ml (Hoppman et al., 2009).

La muestras de tejido adiposo son obtenidas mediantes cánulas de lipoaspiración conectadas a presión negativa entre -400 a $600 \mathrm{mmHg}$ (Fig. 2). Este procedimiento genera fragmentos de tejido cuyo tamaño varían dependiendo del grosor de la cánula, no se altera significativamente la viabilidad celular. Se transportan en frascos de $50 \mathrm{cc} \mathrm{a} 4^{\circ} \mathrm{C}$ hasta su procesamiento según la técnica descrita por Zuk et al.

Se lava la muestra con solución buffer-fosfato (PBS) en igual cantidad, agitación, eliminación de las células hemáticas, solución salina y anestésico local, obtención de la fracción estromal. Digestión de la matriz extracelular con Colagenasa II al 0,075\% por 30 minutos a $37^{\circ} \mathrm{C}$. Inactivación de la enzima con igual volumen de medio de cultivo. Centrifugación de la muestra a $1200 \mathrm{~g}$ por 10 minutos, se obtiene precipitado de alta densidad. El pellet obtenido es resuspendido en medio de cultivo y puesto en placas Falcon ${ }^{\circledR}$ de $100 \mathrm{~mm}$. El medio de cultivo se compone de DMEM + 10\% FBS + Penicilina-estreptomicina-anfotericina $\mathrm{B}$ y glutamina $100 \mathrm{UI} / \mathrm{ml}$. Se mantiene a $37^{\circ} \mathrm{C}$ y $5 \%$ de CO 2 . Se lava a las $24 \mathrm{hrs}$ con PBS para eliminar las células no adherentes al plástico. Se mantiene en el incubador con cambio del medio 2 veces a la semana. Al obtener confluencia $\left(5^{\circ}\right.$ a $7^{\circ}$ día) se realiza tripsinisación para pasar al segundo pasaje (Meruane et al., 2009) (Fig.3).

El tiempo de doblaje celular es entre 2 a 4 días dependiendo del medio de cultivo y el pasaje en que se encuentre (Mitchell \& McIntosh, 2006). Si comparamos la capacidad proliferativa las BM-MSCs llegan hasta 
el pasaje $\mathrm{N}^{\circ} 15$ mientras las las ASCs llegan a sobrepasar el pasaje $\mathrm{N}^{\circ} 20$ (Lee et al., 2004). Con pasajes prologados por más de 4 meses, se ha observado que las ASCs pueden ir a la transformación maligna, al menos en 1 reporte se ha demostrado anormalidades cariotípicas con frecuencia > a $30 \%$ y cuando son implantadas en una rata inmunodeficiente se forman tumores hasta en 50\% (Rubio et al., 2005). Estos resultados nos indican que la manipulación de ASCs debe ser con cautela.

Nomeclatura a utilizar, Criterios para definir célula multipotencial, características moleculares. En el año 2000 la Sociedad Internacional de Terapia Celular (ISCT) concluye que el término "célula troncal" para denominar a estas células adherentes al plástico no tiene mucho soporte, si bien el término MSCs (mesenchymal stem cells) está arraigado en todos los científicos del área, se sugiere utilizar el término "Células Estromales Mesenquimáticas Multipotentes", se puede seguir utilizando el acrónimo MSCs pero con este concepto detrás (Horwitz et al., 2005. Según ésto el término correcto para las células troncales derivadas del tejido adiposo es "células estromales derivadas del tejido adiposo" (ADSCs) pero lo más común actualmente es denominarlas ASCs como acrónimo y BM-MSCs a las células troncales derivadas de la médula ósea, aunque a estas últimas se les sigue denominando MSCs en forma genérica.

La ISCT ha establecido criterios para poder denominar a una célula como MSC. Primero las MSC deben ser adherentes al plástico en condiciones de cultivo estándar. Segundo, $\geq 95 \%$ de las MSC medido por citometría de flujo debe expresar CD105, CD73 y CD90 y perder la expresión ( $\leq 2 \%$ positivo) para CD45, CD34, CD14 o CD11b, CD79a o CD19 y HLA clase II. Tercero estas células deben ser capaces de diferenciarse en osteoblastos, adipositos y condroblastos en condiciones de cultivo estándar (Dominine et al., 2006) (Tabla I).

Los inmunofenotipos celulares de superficie tales como los marcadores CD (determinados por citometría de flujo) han sido investigados por varios autores. Comparan- do la expresión de marcadores en ASCs v/s BM-MSCs v/s UCB-MSCs (umbilical cord blood) más del $90 \%$ expresan CD44, CD73, CD29, CD90 y HLA I y ninguno expresa el HLA II2. Una de las principales controversias es la expresión de CD34 el cual es un marcador ampliamente utilizado para células troncales hematopoyéticas que se describe casi ausente en las ASCs (Lee et al.; Kern et al., 2006), Según Mitchell et al. lo expresan en más del $60 \%$ antes pasaje $\mathrm{N}^{\circ} 4$ para luego perderse casi por completo (Mitchel \& McIntosh).

$\mathrm{Al}$ igual que las BM-MSCs las ASCs se las considera inmunoprivilegiadas no sólo por el hecho de carecer de HLA II, sino porque tienen la habilidad de suprimir la reacción linfocítica mixta, en consecuencia se las puede injertar en forma alogénica (Puissant et al., 2005; Uccelli et al., 2007).

Una de las propiedades funcionales de las ASCs es que no sólo poseen la capacidad de multidiferenciación sino que además secretan potentes factores de crecimiento como el factor de crecimiento vascular endotelial (VEGF), factor de crecimiento hepatocítico (HGF) y factor de crecimiento símil a la insulina, especialmente en respuesta a la hipoxia (Rehman et al., 2004) y al factor de necrosis tumoral- $\partial$ mediado por un mecanismo dependiente de proteína kinasa p38 (Wang et al., 2006).

Para una mayor caracterización de las MSCs v/s fibroblastos, ya que su aspecto morfológico es muy similar, se ha analizado la expresión genética global encontrándose 25 genes (incluyendo fibronectina, ECM2, IDI, NFIB, HOXA5 y HOXB6) con sobreexpresión en el grupo de MSCs (Wagner et al., 2005). Comparando ASCs v/s BMMSCs menos del 1\% de los genes tiene diferente expresión (Lee et al., 2004).

Capacidad de diferenciación de las ASCs. Las ASCs tienen la capacidad de diferenciarse en células de origen mesodérmico como adipocitos (Zuk et al.), fibroblastos, miocitos (Mizuno et al., 2002), osteocitos (Zuk et al.; Halvorsen et al., 2001; Hicok et al., 2004) y condrocitos

Tabla I. Criterios para Identificar MSC (Dominici et al., 2006).

\begin{tabular}{|c|c|c|}
\hline \multicolumn{3}{|l|}{ Criterios } \\
\hline \multicolumn{3}{|c|}{ 1. Adherencia al plástico en condiciones de cultivo estándar } \\
\hline \multirow[t]{5}{*}{ 2. Fenotipo } & $\begin{array}{l}\text { Positivo ( } \geq 95 \% \text { ) } \\
\text { CD105 }\end{array}$ & $\begin{array}{l}\text { Negativo }(\leq 2 \%) \\
\text { CD45 }\end{array}$ \\
\hline & CD73 & CD34 \\
\hline & CD90 & CD14 o CD11b \\
\hline & & CD79_o CD19 \\
\hline & & HLA-DR \\
\hline \multicolumn{3}{|c|}{$\begin{array}{l}\text { 3. Diferenciación in Vitro: osteoblastos, adipocitos, } \\
\text { condroblastos (demostrado por tinción del cultivo celular) }\end{array}$} \\
\hline
\end{tabular}


(Zuk et al.; Erickson et al., 2002), proceso denominado diferenciación linaje-específica. Dentro de estos tipos celulares mesodérmicos el proceso de diferenciación puede cambiar por ejemplo por soobreexpresión de un factor de transcripción específico de cada linaje. Así la sobreexpresión de PPAR $\gamma$ en fibroblastos o miocitos resulta en diferenciación adipogénica. Este proceso es denominado "transdiferenciación" (Hong \& Yaffe, 2006). Llama la atención que las ASCs no sólo tienen el potencial de diferenciarse en células y tejidos de origen mesodérmico. Cada vez hay más evidencia de la capacidad de las ASCs para diferenciarse en tejidos de origen distinto como neuronas (Safford et al., 2002; Ashjian et al., 2003), células pancreáticas endocrinas (Timper et al., 2006; Lee et al., 2008), hepatocitos (Seo et al., 2005), células endoteliales (Miranville et al., 2004; Cao et al., 2005), cadiomiocitos (Planat-Benard et al., 2004) y células epiteliales (Brzoska et al., 2006). A este proceso Shäffler et al. (2007) le han denominado "diferenciación cruzada".

Los factores de transcripción y los eventos moleculares que llevan a la diferenciación en cualquier linaje mesodérmico son bien conocidos (Shäffler et al.)(TablaIII). Sin embargo, previo a que la diferenciación ocurra, la célula troncal debe ser asignada a cierto linaje, Hong (2006) han descrito un coactivador de transcripción denominado "TAZ" que funciona como un "modulador molecular" al activar un factor e inhibir a otro simultáneamente, así puede determinar la diferenciación de una célula hacia la línea ósea o adiposa en forma excluyente.

En la Tabla II se representan las diferentes líneas de diferenciación publicadas hasta el momento, así como la composición de los medios de cultivo y factores de creci- miento respectivos. Además en la Tabla III mencionamos los genes y factores de transcripción relacionados con los 4 linajes mesodérmicos básicos así como sus marcadores y tinciones específicas.

Diferenciación Adipogénica: Las ASCs poseen la capacidad de diferenciarse en linaje adiposo con todas sus características funcionales tales como actividad lipolítica ante la estimulación con catecolaminas, secreción de adiponectina y leptina (Dicker et al., 2005). Se ha regenerado nuevo tejido adiposo en ratas mediante la inyección de esferas que incluyen ASCs diferenciadas (Choi et al., 2005). La capacidad de diferenciación en este linaje es de un 100\% para ASCs v/s 94\% para BM-MSCs v/s 0\% de UCB-MSCs (Kern et al.). El futuro de la regeneración de tejido adiposo será restituir la morfología de partes blandas.

Diferenciación Osteogénica: En el medio de cultivo adecuado y utilizando una matriz extracelular artificial se obtiene un diferenciación bastante exitosa. Las células generadas poseen la capacidad mecanosensitiva similar al hueso (Knippenberg et al., 2005). Las ASCs tratadas con BMP-2 recombinante se diferencian a la línea ósea rápidamente (Dragoo et al., 2003). Cui et al. (2007) evaluaron el uso de ASCs en una matriz de coral para reparar un defecto craneal de $2 \times 2 \mathrm{~cm}$ en un modelo canino con $84 \%$ de cicatrización v/ s un $25 \%$ en el control con un seguimiento de 2 años.

Diferenciación Condrogénica: Adicional al medio de cultivo que describe Zuk et al., con TGF-b1 la adición de BMP4, BMP-6, BMP-7 inducen la diferenciación (Shäffler et al.). Se describen diferencias en la capacidad de diferenciación de ASCs v/s BM-MSCs, pero éstas se deberían sólo a un menor tiempo de cultivo (Fraser et al., 2005).

Tabla II. Potencial de Diferenciación y Factores Asociados

\begin{tabular}{|c|c|c|}
\hline Tipo de Diferenciación & Factor Inductivo & Referencia \\
\hline Adiposo & Dexametasona, IBMX, Indometacina, Insulina, Tiazolidona & Zuk et al., 2001. \\
\hline Óseo & Ácido ascórbico, BMP-2, dexametasona, $1,25(\mathrm{OH})_{2} \mathrm{D}_{3}$ & $\begin{array}{l}\text { Halvorsen et al., 2001; Hicok } \\
\text { et al., } 2004 \text {. }\end{array}$ \\
\hline Cartilaginoso & $\begin{array}{l}\text { Ácido ascórbico, BMP-6, BMP-7, FGF-2, TGF-1, TGF-2, TGF-3, } \\
\text { dexametasona, IGF1, insulina. }\end{array}$ & $\begin{array}{l}\text { Schäffler } \text { et al., 2007; Erickson } \\
\text { et al., 2002; Estes } \text { et al., } 2006 . \text {. }\end{array}$ \\
\hline Muscular & Dexametasona, suero de caballo & Mizuno et al., 2002. \\
\hline Cardiomuscular & Transferrina, IL-3, IL-6, VEGF & Planat-Bénard et al., 2004. \\
\hline Endotelial & $\begin{array}{l}\text { Medio es pecial (EGM-2-MV; Cambrex), Ac. Ascórbico, EGF, } \\
\text { bFGF, hidrocortizona }\end{array}$ & $\begin{array}{l}\text { Miranville et al., 2004; Cao et } \\
\text { al., } 2005 .\end{array}$ \\
\hline Neuronal & Hidroxinisolona, Ácido valproico, Insulina & $\begin{array}{l}\text { Safford et al., 2002, Ashjian et } \\
\text { al., } 2003\end{array}$ \\
\hline Pancreático & activina-A, exendina- 4 , HGF, pentag astrina & $\begin{array}{l}\text { Timper et al., 2006; Lee et al., } \\
2008 .\end{array}$ \\
\hline Hepático & HGF, Oncostatina M y dimetil-sulfóxido & Seo et al., 2005. \\
\hline Epitelial & Ácido trans-retinoico & Brzoska et al., 2006. \\
\hline
\end{tabular}


Tabla III. Linajes mesodérmicos, tinciones y genes implicados.

\begin{tabular}{|c|c|c|c|}
\hline & Determinante específico del linaje & $\begin{array}{l}\text { Tinciones histológicas/ } \\
\text { inmunohistoquímicas }\end{array}$ & $\begin{array}{l}\text { Factores de transcripción, de } \\
\text { crecimiento, kinasas. }\end{array}$ \\
\hline Adipogénica & Acumulación lipídica & Rojo oleoso & $\begin{array}{l}\text { PPAR } \gamma / \mathrm{RXR} \alpha \\
\mathrm{C} / \mathrm{EBP} \partial, \beta, \partial \\
\text { ADD1/SREBP1c } \\
\text { KROX-20, KLF-5 }\end{array}$ \\
\hline Osteogénica & $\begin{array}{l}\text { Actividad Fosfatasa Alcalina, } \\
\text { Producción de matriz calcificada }\end{array}$ & $\begin{array}{l}\text { Fosfatasa Alcalina, } \\
\text { Von Kossa }\end{array}$ & $\begin{array}{l}\text { Runx-2, Tbx-3 } \\
\text { BMP-2, Notch-1 } \\
\text { Osx, Dix5, Msx2 } \\
\text { Menin, Shh }\end{array}$ \\
\hline Condrogénica & $\begin{array}{l}\text { Matriz de proteoglicanos sulfatados, } \\
\text { Síntesis de Colágeno tipo II }\end{array}$ & $\begin{array}{l}\text { Azul alcian, } \\
\text { Anticuerpo monoclonal para } \\
\text { colágeno II }\end{array}$ & $\begin{array}{l}\text { BMP-4,-6,-7 } \\
\text { FGF-2, TGFß } \\
\text { Sox-9 } \\
\text { Brachyury }\end{array}$ \\
\hline Miogénica & $\begin{array}{l}\text { Multinucle ación, } \\
\text { Expresión de MyoD1 }\end{array}$ & $\begin{array}{l}\text { Anticuerpos monoclonales para } \\
\text { Miosina y MyoD1. }\end{array}$ & $\begin{array}{l}\text { MyoD, Myf5, Miogenina } \\
\text { MRF4, MEF2 } \\
\text { Pax-3, Pax-7 }\end{array}$ \\
\hline
\end{tabular}

Diferenciación Miogénica: Luego que Mizumo et al. (2002) describiera que las ASCs en medio suplemetado con hidrocortizona más dexametasona formaba células multinucleadas con miotúbulos después de 3 semanas, se han génerado varios estudios preclínicos dentro de los cuales cabe destacar el de Bacau et al. (2004) que inyecta células diferenciadas al $3^{\circ}$ día en músculo tibial anterior lesionado con mejoría mayor que el control. Rodriguez et al. (2005) reporta la regeneración muscular en un modelo de ratas mdx (ratas con distrofía muscular de Duchenne).

Diferenciación cardiogénica: Las ASCs cultivadas en medio de metilcelulosa semisólida con IL-3 (interleuquina3), IL-6 más VEGF diferencian células con actividad marcapaso, expresión genética específica de células cardíacas y capacidad de responder a estímulos colinérgicos y adrenérgicos (Planat-Bénard et al., 2004). En modelos de ratas la inyección intraventricular de ASCs posterior e isquemia miocárdica aguda logra una mejora en la función ventricular a las 12 semanas de seguimiento, eso sí, sin aumentar significativamente la masa muscular (SchenkeLayland et al., 2009).

Diferenciación endotelial: El potencial proangiogénico parte del hecho que estas células liberan VEGF, HGF, FGF2, TGF-b (Rechman et al., 2004; Wang et al., 2006; Lu et al., 2008). Esto las hace utilizables para la terapia regenerativa celular y para tratar la los problemas relacionados con la isquemia reperfusión (Miranville et al.; Cao et al.). $\mathrm{Al}$ administrar VEGF in Vitro se expresan los marcadores endoteliales. Lu et al. (2008) demuestra en un modelo de colgajos en ratas que la viabilidad de éstos aumenta con la inyección de ASCs, posteriormente Uysal et al. (2009) nos muestra el mismo modelo de colgajo sometido esta vez a isquemia/reperfusión con aumento en la viabilidad del colgajo en más de un $40 \%$ así como los factores de crecimiento vasculares asociados.

Diferenciación Neurogénica: Kang et al. (2003) realiza un estudio con ASCs humanas diferenciadas en células neuronales e injectadas en un modelo experimental de isquemía cerebral en ratas con resultados positivos, mejorando déficit funcionales.

Diferenciación Pancreática: Timper et al. (2006) obtienen diferenciación pancreática in Vitro de ASCs al adicionar los factores de diferenciación activina-A, exendina-4, HGF y pentagastrina. Las células diferenciadas logran producir insulina, glucagón y somatostatina. Lee et al. (2008) obtiene resultados similares añadiendo al cultivo de ASCs "extracto de páncreas".

Diferenciación Hepática: Seo et al. (2005) trata ASCs con HGF, Oncostatina M y dimetil-sulfóxido obteniendo una línea que produce albumina y a-fetoproteina. Adicionalmente estas células poseen la habilidad de depurar lipoproteínas de baja densidad y producir urea. Kim et al. (2003) administra ASCs en forma endovenosa a ratas después de una hepatectomía parcial obteniendo integración hepática de éstas.

Diferenciación Epitelial: la diferenciación queratinocítica es inducida por ácido trans-retinoico en una dosis que no inhiba la proliferación excesivamente (Brzoska et al., 2005). En ratas diabéticas y en heridas tratadas con mitomicina el implante ASCs más una matriz dérmica acelera la cicatrización (Nanbu et al., 2007, 2009) 
Aplicaciones Clínicas. Dentro de los primeros casos de uso clínico se encuentra la utilización de ASCs para tratar grandes defectos de calota asociado a "pegamento de firina" y una matriz biodegradable (Lendeckel et al., 2004). Se ha utilizado también en la reconstrucción de mandíbula en una paciente sometetida a hemimandibulectomía con posterior reconstracción colgajo más matriz ósea más BMP-2 más ASCs autólogas con éxito en la formación de hueso a los 8 meses (Mesimäki et al., 2009).

Garcia-Olmo et al. (2009) han publicado la utilización de ASCs para el cierre de fístulas enterocutáneas en pacientes con enfermedad de Crohn ya sea en forma directa como aplicadas luego de cultivo (expandidas), obteniendo de un $75 \%$ en este último tratamiento. También se las ha utilizado con éxito en 1 paciente para el cierre de una fístula traqueomediastínica producida por radioterapia (Alvarez et al., 2008).

La inyección de grasa autóloga lipoaspirada más ASCs para aumento de tejido blandos constituye un nuevo procedimiento denominado cell-assisted lipotransfer (CAL) descrito por Matsumoto et at. (2006) quien plantea que esto da un $35 \%$ más de supervivencia al injerto graso. Posteriormente Yoshimura et al. (2008) describe este procedimiento para mamoplastía de aumento sin prótesis en 40 pacientes.

Rigotii et al. (2007) ha descrito la inyección de lipoaspirado purificado en úlceras cutáneas de difícil cicatrización secundarias a radioterapía, con éxito en 20 pacientes.

Un hecho interesante que ha tenido aplicación clínica es el uso de ASCs en transplante de órganos cuando hay un rechazo agudo inmanejable con corticoides. Esto basado en la hipótesis que las ASCs disminuyen la respuesta inmune del huésped (Uccelli et al.). Fang \& Song (2007) encontraron respuesta favorable en 5 de 6 casos con este cuadro.
Finalmente cabe mencionar que se están realizando estudios clínicos para evaluar la respuesta de ASCs en infarto agudo al miocardio e insuficiencia cardíaca, se piensa que podrían ser igual de efectivas que las BM-MSCs de las cuales se ha publicado una mejora en la función ventricular de un $6,1 \%$ con su uso en un metaanalisis que incluye 516 pacientes randomizados (Singh et al., 2009).

\section{CONCLUSIÓN}

El acceso fácil y repetible del tejido adiposo provee claramente una ventaja en la obtención de MSCs comparado con la médula ósea. La técnica de cultivo es simple de realizar como procedimiento estandarizado, aunque con el propósito de utilización clínica lo más sensato sería utilizar un ambiente cerrado y estéril para que su manipulación minimice los riesgos de contaminación. Queda expuesto en esta revisión que tanto ASCs como BM-MSCs poseen una capacidad de diferenciación parecida al menos para los tejidos de origen mesodérmico. Para el resto de las líneas no mesodérmicas las publicaciones son más recientes pero el potencial es evidente. En la diferenciación de tejidos mesodérmicos las claves moleculares se conocen, para el resto falta información. Se entiende que los efectos positivos encontrados no sólo se deben a la capacidad de diferenciación de las ASCs, sino también la liberación de factores paracrinos angiogénicos y antiapoptóticos más el efecto inmunosupresor.

Los preparados comerciales de ASCs ya se encuentran a la venta, provenientes de lipoaspirados humanos (STEMPRO®, Invitrogen Corporation 5791 Van Allen Way Carlsbad, CA 92008 USA) para uso de laboratorio principalmente, pero podría ser el inicio para la terapia con células alogénicas en pacientes que lo requieran y en aquellos que no se pueda realizar el procedimiento de lipoaspiración y cultivo por apremio temporal (ej: rechazo agudo de órgano transplantado, infarto agudo al miocardio).

MERUANE, M. \& ROJAS, M. Adipose tissue derived stem cells. Int. J. Morphol., 28(3):879-889, 2010.

SUMMARY: In order to regenerate organs and functions has become known to the stem cells. Adult stem cells have the advantage that can be obtained from adult individuals without the ethical problems that brings the use of embryonic cells. Obtaining stem cells from adipose tissue (ASCs) has been a revolution because these cells can be obtained in large quantities with minimal discomfort and even with local anesthesia. Comparing the ASCs versus stem cells derived from bone marrow (BM-MSCs) their phenotypic characteristics and potential for differentiation are very similar. In this review we focus on the technique for obtaining ASCs, its molecular characteristics, their capacity for differentiation in mesodermal and no-mesodermal lineages, the most relevant preclinical and clinical trials executed at this time, as well as prospects for future use. 


\section{REFERENCIAS BIBLIOGRÁFICAS}

Ailhaud, G. \& Grimaldi, P. Cellular and molecular aspects of adipose tissue development. Annu. Rev. Nutr., 12:207-33, 1992.

Almeida, K. A.; Campa, A.; Alonso-Vale, M. I. C.; Lima, F. B.; Daud, E. D. \& Stocchero, I. N. Fracción vascular estromal de tejido adiposo: cómo obtener células madre y su rendimiento de acuerdo a la topografía de las áreas donantes: estudio preliminar. Cir. Plást. Iberolatinoam., 34:71-9, 2008.

Alvarez, P. D.; García-Arranz, M.; Georgiev-Hristov, T.; García-Olmo, D. A new bronchoscopic treatment of tracheomediastinal fistula using autologous adiposederived stem cells. Thorax, 63:374-6, 2008.

Ashjian, P. H.; Elbarbary, A. S.; Edmonds, B.; DeUgarte, D.; Zhu, M., Zuk, P. A.; Lorenz, H. P.; Benhaim, P. \& Hedrick, M. H. In vitro differentiation of human processed lipoaspirate cells into early neural progenitors. Plast. Reconst. Surg., 111:1922-31, 2003.

ASPS. Procedures realized by the surgeons certified by the American Board of Plastic Surgery, 2007.

Bacou, F.; Boubaker el Andalousi, R.; Daussin, P-A.; Micallef, J-P.; Levin, J. M.; Chammas, M.; Casteilla, L.; Reyne, Y. \& Nouguès, J.Transplantation of adipose tissue-derived stromal cells increases mass and functional capacity of damaged skeletal muscle. Cell Transplant., 13:103-11, 2004.

Bruder, S. P.; Jaiswal, N. \& Haynesworth, S. E. Growth kinetics, self-renewal, and the osteogenic potential of purified human mesenchymal stem cells during extensive subcultivation and following cryopreservation. J. Cell Biochem., 64:278-94, 1997.

Brzoska, M.; Geiger, H.; Gauer, S. \& Baer, P. Epithelial differentiation of human adipose tissue-derived adult stem cells. Biochem. Biophys. Res. Commun., 330:142-50, 2005.

Butler, D. L.; Goldstein, S. A. \& Guilak, F. Functional tissue engineering: the role of biomechanics. $J$. Biomech. Eng., 122:570-5, 2000.

Cao, Y.; Sun, Z.; Liao, L.; Meng, Y.; Han, Q. \& Zhao, R. C. Human adipose tissue-derived stem cells differentiate into endothelial cells in vitro and improve postnatal neovascularization in vivo. Biochem. Biophys. Res. Commun., 332:370-9, 2005.

Chamberlain, G.; Fox, J.; Ashton, B. \& Middleton, J. Concise review: mesenchymal stem cells: their phenotype, differentiation capacity, immunological features, and potential for homing. Stem Cells, 25:2739-49, 2007.

Choi, Y. S.; Park, S. N. \& Suh, H. Adipose tissue engineering using mesenchymal stem cells attached to injectable PLGA spheres. Biomaterials, 26:585563, 2005.

Cui, L.; Liu, B.; Liu, G.; Zhang, W.; Cen, L.; Sun, J.; Yin, S.; Liu, W. \& Cao, Y. Repair of cranial bone defects with adipose derived stem cells and coral scaffold in a canine model. Biomaterials, 28:5477-86, 2007.

Davenport, R. J. What controls organ regeneration? Science, 309:84, 2005.

Dicker, A.; Le Blanc, K.; Aström, G.; van Harmelen, V.; Götherström, C.; Blomqvist, L.; Arner, P. \& Rydén, M. Functional studies of mesenchymal stem cells derived from adult human adipose tissue. Exp. Cell Res., 308:283-90, 2005.

Dominici, M.; Le Blanc, K.; Mueller, I.; SlaperCortenbach, I.; Marini, F.; Krause, D.; Deans, R.; Keating, A.; Prockop, Dj. \& Horwitz, E. Minimal criteria for defining multipotent mesenchymal stromal cells. The international society for cellular therapy position statement. Cytotherapy, 8(4):315-7, 2006.

Dragoo, J. L.; Choi, J. Y.; Lieberman, J. R.; Huang, J.; Zuk, P. A.; Zhang, J.; Hedrick, M. H. \& Benhaim, P. Bone induction by BMP-2 transduced stem cells derived from human fat. J. Orthop. Res., 21:622-9, 2003.

Elwood, D. \& Pomposelli, J. J. Hepatobiliary surgery: lessons learned from live donor hepatectomy. Surg. Clin. North. Am., 86:1207-17, 2006.

Erickson, G. R.; Gimble, J. M.; Franklin, D. M.; Rice, H. E.; Awad, H. \& Guilak, F. Chondrogenic potential of adipose tissue-derived stromal cells in vitro and in vivo. Biochem. Biophys. Res. Commun., 290:763-9, 2002. 
Estes, B. T.; Wu, A. W. \& Guilak, F. Potent induction of chondrocytic differentiation of human adipose-derived adult stem cells by bone morphogenetic protein 6 . Arthritis Rheum., 54:1222-32, 2006.

Fang, B. \& Song, Y. Favorable response to human adipose tissue-derived mesenchymal stem cells in steroidrefractory acute graft-versus-host disease. Transplant. Proc., 39:3358-62, 2007.

Fraser, J. K.; Wulur, I.; Alfonso, Z. \& Hedrick, M. H. Fat tissue: an underappreciated source of stem cells for biotechnology. Trends Biotechnol., 24:150-4, 2006.

Friedenstein, A. J.; Deriglasova, U. F.; Kulagina, N. N.; Panasuk, A. F.; Rudakowa, S. F.; Luriá, E. A. \& Ruadkow, I. A. Precursors for fibroblasts in different populations of hematopoietic cells as detected by the in vitro colony assay method. Exp. Hematol., 2(2):8392, 1974.

Garcia-Olmo, D.; Herreros, D.; Pascual, M.; Pascual, I.; De-La-Quintana, P.; Trebol, J. \& Garcia-Arranz, M. Treatment of enterocutaneous fistula in Crohn's Disease with adipose-derived stem cells: a comparision of protocols with and without cell expansion. Int. J. Colorectal Dis., 24:27-30, 2009.

Gimble, J.; Katz, A. \& Bunnell, B. Adipose-derived stem cells for regenerative medicine. Circ. Res., 100:124960, 2007.

Giordano, A.; Galderisi, U. \& Marino, I. R. From the laboratory bench to the patient's bedside: an update on clinical trials with mesenchymal stem cells. J. Cell. Physiol., 211:27-35, 2007.

Halvorsen, Y. D.; Franklin, D.; Bond, A. L.; Hitt, D. C.; Auchter, C.; Boskey, A. L.; Paschalis, E. P.; Wilkison, W. O. \& Gimble, J. M. Extracellular matrix mineralization and osteoblast gene expression by human adipose tissue-derived stromal cells. Tissue Eng., 7:729-41, 2001.

Hausman, G. J. \& Hausman, D. B. Search for the preadipocyte progenitor cell. J. Clin. Invest., 116:3103-7, 2006.

Hicok, K. C.; Du Laney, T. V.; Zhou, Y. S.; Halvorsen, Y. D.; Hitt, D. C.; Cooper, L. F. \& Gimble, J. M. Human adipose-derived adult stem cells produce osteoid in vivo. Tissue Eng., 10:371-80, 2004.
Hong, J. H. \& Yaffe, M. A b-catenin-like molecule that regulates mesenchymal stem cell differentiation. Cell Cycle, 5(2):176-9, 2006.

Housman, T. S.; Lawrence, N.; Mellen, B. G.; George, M. N.; Filippo, J. S.; Cerveny, K. A.; DeMarco, M.; Feldman, S. R. \& Fleischer, A. B. The safety of liposuction: results of a national survey. Dermatol. Surg., 28:971-8, 2002.

Hoppman, R.; González, D.; Hasbún, A.; Meruane, M. \& Correa, O; Remodelamiento Abdominal: Análisis y Técnica Empleada. XXXVI Simposio Anual Internacional de Cirugía Plástica-Estética, Puerto Vallarta, Jalisco, México, Noviembre, 2009.

Horwitz, E. M.; Le Blanc, K.; Dominici, M.; Mueller, I.; Slaper-Cortenbach, I.; Marini, F. C.; Deans, R. J.; Krause, D. S.; Keating, A. \& International Society for Cellular Therapy. Clarification of the nomenclature for MSC: The International Society for Cellular Therapy position statement. Cytotherapy, 7(5):393$5,2005$.

Kang, S. K., Lee, D. H.; Bae, Y. C.; Kim, H. K.; Baik, S. Y.; Jung, J. S.; Kunlin, J. \& Greenberg, D. A. Improvement of neurological deficits by intracerebral transplantation of human adipose tissue-derived stromal cells after isquemia in rats. Exp. Neurol., 183:355-66, 2003.

Kern, S.; Eichler, H.; Stoeve, J.; Klüter, H. \& Bieback, K. Comparative analysis of mesenchymal stem cells from bone marrow, umbilical cord blood, or adipose tissue. Stem Cells, 24:1294-301, 2006.

Kim, D. H.; Je, C. M.; Sin, J. Y. \& Jung, J. S. Effect of partial hepatectomy on in vivo engraftment after intravenous administration of human adipose tissue stromal cells in Mouse. Microsurgey, 23:424-31, 2003.

Knippenberg, M.; Helder, M. N.; Doulabi, B. Z.; Semeins, C. M.; Wuisman, P. I. \& Klein-Nulend, J. Adipose tissue-derived mesenchymal stem cells acquire bone cell-like responsiveness to fluid shear stress on osteogenic stimulation. Tissue Eng., 11:1780-8, 2005.

Matsumoto, D.; Sato, K.; Gonda, K.; Takaki, Y.; Shigeura, T.; Sato, T.; Aiba-Kojima, E.; Iizuka, F.; Inoue, K.; Suga, H. \& Yoshimura, K. Cell-assisted lipotransfer: Supportive use of human adipose-derived cells for soft tissue augmentation with lipoinjection. Tissue Eng., 12:3375-82, 2006. 
Meruane, M.; Rojas, M.; Castro, R. \& Hoppmann, R. Técnica para la obtención y cultivo de células troncales adultas desde el tejido adiposo. XII Congreso de Cirugía Plástica del Cono Sur Americano, Viña del Mar, Octubre 2009.

Mesimäki, K.; Lindroos, B.; Törnwall, J.; Mauno, J.; Lindqvist, C.; Kontio, R.; Miettinen, S. \& Suuronen, R. Novel maxillary reconstruction with ectopic bone formation by GMP adipose stem cells. Int. J. Oral Maxillofac. Surg., 38:201-9, 2009.

Miranville, A.; Heeschen, C.; Sengenès, C.; Curat, C. A.; Busse, R. \& Bouloumié, A. Improvement of postnatal neovascularization by human adipose tissue-derived stem cells. Circulation, 110:349-55, 2004.

Mitchell, J. \& McIntosh, K. Inmunophenotype of human adipose-derived cells: temporal changes in stromalassociated stem cell-asociated markers. Stem Cells, 24:376-85, 2006.

Mizuno, H.; Zuk, P. A.; Zhu, M.; Lorenz, H. P.; Benhaim, P. \& Hedrick, M. H. Myogenic differentiation by human processed lipoaspirate cells. Plast. Reconstr. Surg., 109:199-209, 2002.

Nambu, M.; Kishimoto, S.; Nakamura, S.; Mizuno, H.; Yanagibayashi, S.; Yamamoto, N.; Azuma, R.; Nakamura, S.; Kiyosawa, T.; Ishihara, M. \& Kanatani Y. Accelerated wound healing in healing-impaired mice by autologous adipose tissue-derived stromal cells combined with atelocollagen matrix. Ann. Plast. Surg., 62(3):317-21, 2009.

Nambu, M. ; Ishiara, M.; Nakamura, S.; Mizuno, H.; Yanagibayashi, S.; Kanatani, Y.; Hattori, H.; Takase, B.; Ishizuka, T.; Kishimoto, S.; Amano, Y.; Yamamoto, N.; Azuma, R. \& Kiyosawa, T. Enhanced healing of mitomycin c-treated wounds in rats using inbred adipose tissue-derived stromal cells within an atelocollagen matrix. Wound Repair Regen., 15:50510, 2007.

Nogi, T. \& Levin, M. Characterization of innexin gene expresión and functional roles of gap-junctional communications in planarian regeneration. Dev. Biol., 287:314-35, 2005.

Lee, J.; Han, D. J. \& Kim, S. C. In Vitro differentiation of human adipose tissue stem cells into cells with pancreatic phenotype by regenerating pancreas extract. Biochem. Biophys. Res. Commun., 375:547-51, 2008.
Lee, R. H.; Kim, B.; Choi, I.; Kim, H.; Choi, H. S.; Suh, K.; Bae, Y. C. \& Jung, J. S. Characterization and expression analysis of mesenchymal stem cells from human bone marrow an adipose tissue. Cell Physiol. Biochem., 14:311-24, 2004.

Lendeckel, S.; Jödicke, A.; Christophis, P.; Heidinger, K.; Wolff, J.; Fraser, J. K.; Hedrick, M. H.; Berthold, L. \& Howaldt, H. P. Autologous stem cells (adipose) and fibrin glue used to treat widespread traumatic calvarial defects: case report. J. Craniomaxillofac. Surg., 32:370-3, 2004.

Lu, F.; Mizuno, H.; Uysal, C. A.; Cai, X.; Ogawa, R. \& Hyakusoku, H. Improved viability of random pattern skin flaps through the use of adipose-derived stem cells. Plast. Reconstr. Surg., 121(1):50-8, 2008.

Pittenger, M. F.; Mackay, A. M.; Beck, S. C.; Jaiswal, R. K.; Douglas, R.; Mosca, J. D.; Moorman, M. A.; Simonetti, D. W.; Craig, S. \& Marshak, D. R. Multilineage potential of adult human mesenchymal stem cells. Science, 284:143-7, 1999.

Planat-Bénard, V.; Menard, C.; André, M.; Puceat, M.; Perez, A.; Garcia-Verdugo, J. M.; Pénicaud, L. \& Casteilla, L. Spontaneous cardiomyocyte differentiation from adipose tissue stroma cells. Circ. Res., 94:223-9, 2004.

Puissant, B.; Barreau, C.; Bourin, P.; Clavel, C.; Corre, J.; Bousquet, C.; Taureau, C.; Cousin, B.; Abbal, M.; Laharrague, P.; Penicaud, L.; Casteilla, L. \& Blancher, A. Immunomodulatory effect of human adipose tissue-derived adult stem cells: comparison with bone marrow mesenchymal stem cells. Br. J. Haematol., 129:118-29, 2005.

Rehman, J.; Traktuev, D.; Li, J.; Merfeld-Clauss, S.; Temm-Grove, C. J.; Bovenkerk, J. E.; Pell, C. L.; Johnstone, B. H.; Considine, R. V. \& March, K. L.Secretion of angiogenic and antiapoptotic factors by human adipose stromal cells. Circulation, 109:1292-8, 2004.

Rigotti, G.; Marchi, A.; Galié, M.; Baroni, G.; Benati, D.; Krampera, M.; Pasini, A. \& Sbarbati, A. Clinical treatment of radiotherapy tissue damage by lipoaspirate transplant: a healing process mediated by adipose-derived adult stem cells. Plast. Reconst. Surg., 119:1409-22, 2007.

Rodriguez, A. M.; Pisani, D.; Dechesne, C. A.; Turc-Ca- 
rel, C.; Kurzenne, J. Y.; Wdziekonski, B.; Villageois, A.; Bagnis, C.; Breittmayer, J. P.; Groux, H.; Ailhaud, G. \& Dani, C. Transplantation of a multipotent cell population from human adipose tissue induces dystrofhin expresión in inmunocompetent $\mathrm{mdx}$ Mouse. J. Exp. Med., 201:1397-405, 2005.

Rubio, D.; García-Castro, J.; Martín, M. C.; de la Fuente, R.; Cigudosa, J. C.; Lloyd, A. C. \& Bernad, A. Spontaneous human adult stem cell transformation. Cancer Res., 65:3035-9, 2005.

Safford, K. M.; Hicok, K. C.; Halvorsen, Y. D.; Wilkison, W. O.; Gimble, J. M. \& Rice, H. E. Neurogenic differentiation of murine and human adipose-derived stromal cells. Biochem. Biophys. Res. Commun., 294:371-9, 2002.

Schäffler, A. \& Büchler, C. Concise review: Adipose tissue-derived stromal cells - basic and clinical implications for novel cell-based therapies. Stem Cells, 25:818-27, 2007.

Schenke-Layland, K.; Strem, B.; Jordan, M. C.; Deemedio, M. T.; Hedrick, M. H.; Roos, K. P.; Fraser, J. K. \& Maclellan, W. R. Adipose tissue-derived cells improve cardiac function following myocardial infarction. J. Surg. Res., 153:217-23, 2009.

Seo, M. J.; Suh, S. Y.; Bae, Y. C. \& Jung, J. S. Differentiation of human adipose stromal cells into hepatic lineaje in vitro and in vivo. Biochem. Biophys. Res. Commun., 328:258-64, 2005.

Singer, A. J. \& Clark, R. A. Cutaneous wound healing. $N$. Engl. Med., 341:738-46, 1999.

Singh, S.; Arora, R.; Handa, K.; Khraisat, A.; Nagajothi, N.; Molnar, J. \& Khosla, S. Stem cells improve left ventricular function in acute myocardial infarction. Clin. Cardiol., 32:176-80, 2009.

Shipper, M.; Marra, K. G.; Zhang, W.; Donnenberg, A. D. \& Rubin, J. P. Regional anatomic age effects on cell function of human adipose-derived stem cells. Ann. Plast. Surg., 60:538-44, 2008.

Timper, K.; Seboek, D.; Eberhardt, M.; Linscheid, P.; Christ-Crain, M.; Keller, U.; Müller, B. Zulewski, H. Human adipose tissue-derived mesenchymal stem cells differentiate into insulin, somatostatin, and glucagon expressing cells. Biochem. Biophys. Res. Commun., 341:1135-40, 2006.
Uccelli, A.; Pistoia, V. \& Moretta, L. Mesenchymal stem cells: a new strategy for inmunosuppression?. Trends Inmunol., 28(5):221-6, 2007.

Uysal, A. C.; Mizumo, H.; Tobita, M.; Ogawa, R. \& Hyakusoku, H. The effect of adipoose-derived stem cells on isquemia-reperfusion injury: inmunohistochemical and ultraestructural evaluation. Plast. Reconstr. Surg., 124(3):804-15, 2009.

Wagner, W.; Wein, F.; Seckinger, A.; Frankhauser, M.; Wirkner, U.; Krause, U.; Blake, J.; Schwager, C.; Eckstein, V.; Ansorge, W. \& Ho, A. D. Comparative characteristics of mesenchymal stem cells from human bone marrow, adipose tisuue, and umbilical cord blood. Exp. Hematol., 33:1402-16, 2005.

Wang, M.; Crisostomo, P.; Herring, C.; Meldrum, K. K. \& Meldrum, D. R. Human progenitor cells from bone marrow or adipose tissue produce VEGF, HGF and IGF-1 in response to TNF by a p38 mitogen activated protein kinase dependent mechanism. Am. J. Physiol. Regul. Integr. Comp. Physiol., 291:880-4, 2006.

Young, H. E.; Mancini, M. L.; Wright, R. P.; Smith, J. C.; Black, A. C. Jr.; Reagan, C. R. \& Lucas, P. A. Mesenchymal stem cells reside within the connective tissues of many organs. Dev. Dyn., 202:137-44, 1995.

Yoshimura, K.; Sato, K.; Aoi, N.; Kurita, M.; Hirohi, T. \& Harii, K. Cell-assited lipotransfer for cosmetic breast augmentation supportive use of adipose-derived stem/stromal cells. Aesthethic Plast. Surg., 32:48-55, 2008.

Zuk, P. A.; Zhu, M.; Mizumo, H.; Huang, J.; Futrell, J. W.; Katz, A. J.; Benhaim, P.; Lorenz, H. P. \& Hedrick, M. H. Multilineage cells from human adipose tissue: implications for cell-based therapies. Tissue Eng., 7:211-28, 2001.

Dirección para correspondencia:

Dra. Mariana Rojas R.

Laboratorio de Embriología Comparada

Programa de Anatomía y Biología del Desarrollo

Facultad de Medicina, ICBM,

Universidad de Chile

CHILE

Email: dramrojas@hotmail.com

Recibido : 19-07-2010

Aceptado: 28-07-2010 
